\title{
Schedule for IP Address Space Management Guidelines
}

Status of this Memo

This memo provides information for the Internet community. It does not specify an Internet standard. Distribution of this memo is unlimited.

Introduction

This memo suggests a schedule for the implementation of the IP network number allocation plan described in RFC 1366. This schedule is meant to support the implementation and deployment of an address aggregation mechanism for the Internet by proposing an achievable target for which we can all aim. The timely deployment of that aggregation mechanism and the IP addressing plan will help the the size of the Internet router forwarding tables and management of the IP address space. By doing so, it will help the current Internet addressing and routing technology operate during the interim period until the next generation technology is deployed. This interim solution in no way constrains the selection of the next generation addressing and routing technology.

This draft schedule was put together by the FNC Engineering and Planning Group (FEPG) based on the IP addressing plan BOF of the July 1992 IETF meeting, as well as discussions with a number (though, of course, not all) of knowledgeable and interested parties, including the IANA and IR. This draft schedule assumes that the address aggregation mechanism will be available in the Internet by mid-1993. The activities described in this schedule are the precursors to that deployment, and will promote the efficient operation of that mechanism. We feel that our assumptions are realistic and that this schedule can be met. We encourage its open discussion as we move toward community consensus.

Please send comments to topolcicanri.reston.va.us, or to the mailing list ipallocanri.reston.va.us. To be added to this mailing list, send a request to ipalloc-requestenri.reston.va.us.

Note that the references below to an addressing plan and to criteria for regional address registries refer to RFC 1366. 
Draft Implementation Schedule for IP Network Number Allocation Plan:

1) 31 October 92:

The following address allocation procedures are continued:

a) Initial set of criteria for selecting regional address registries will be put into place, and requests from prospective regional registries will be accepted by the IANA.

b) Class A network numbers are practically impossible to obtain.

C) Class B network numbers will continue to be issued only when reasonably justified. If possible, a block of $C^{\prime} s$ will be issued rather than $a \mathrm{~B}$. The requirements for allocating $a$ Class B will become progressively more constrained until the date in step (3).

d) Class $C$ network numbers will be allocated according to the addressing plan. Allocation will be performed by the Internet Registry (IR) if an appropriate regional registry has not yet been designated by the IANA.

2) 14 February 93 :

Re-evaluate and readjust the schedule if necessary.

3) 15 April 93:

a) The IR begins to allocate all networks according to the addressing plan in appropriately sized blocks of Class C numbers.

b) Class B network numbers will be difficult to obtain, following the recommendation of the addressing plan and only issued when justified.

4) 6 June 93:

Expected date that an address aggregation mechanism is available in the Internet.

References

[1] Gerich, E., "Guidelines for Management of IP Address Space", RFC 1366, Merit, October 1992. 


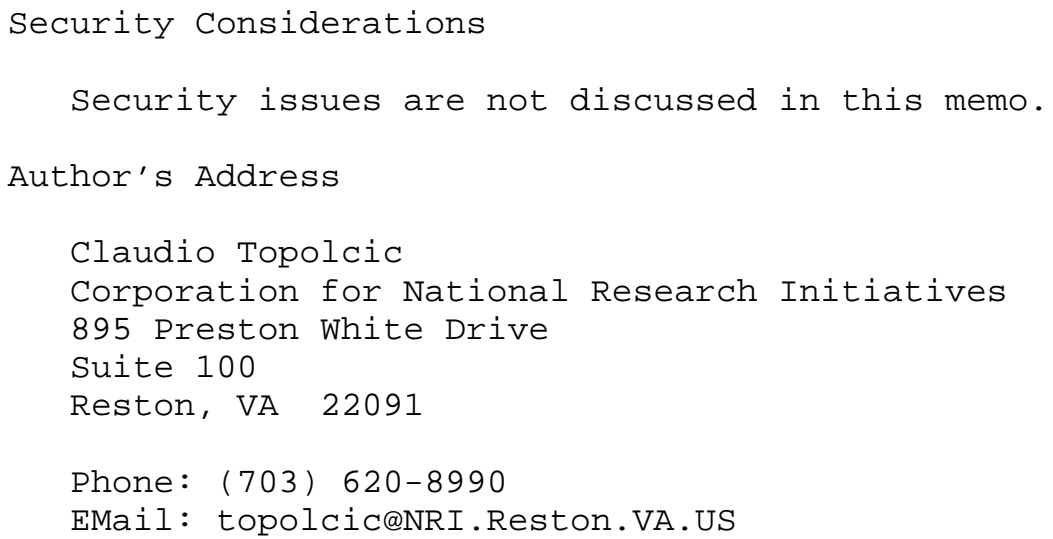

